\title{
Household carbon emission characteristics and adaptive strategies for low carbon community planning
}

\author{
Longbin Zhu ${ }^{1}$, Ying Huang ${ }^{2 *}$, Wenyu Chen ${ }^{1}$ \\ ${ }^{1}$ Nanjing Tech University, Nanjing 211816, China \\ ${ }^{2}$ Nanjing University of Posts and Telecommunications, Nanjing 210023, China
}

\begin{abstract}
Urban communities are important sector for energy saving and emission reduction. Characterization of household carbon emission is critical to the planning of low-carbon communities. Taking data from five communities in Nanjing, China as the empirical research object, this study explores the relationship between household consumer activities and direct carbon emission of household energy consumption based on the Consumer Lifestyle Approach. Using regression analysis, we identify the characteristics of the emission and the four most significant impact factors. Adaptive low carbon strategies are further suggested as how to influence consumer activities by planning of urban communities.
\end{abstract}

\section{Introduction}

As a basic unit for cities to address climate change, urban community is one of the important sectors for energy saving and emission reduction. The International Energy Agency (IEA) data shows that in the OECD countries' overall carbon emissions in 2014, direct carbon emissions accounted for $8 \%$ from the residential sector and $42 \%$ from the electricity and thermal sectors, among which the residential sector accounted for another $12 \%$. In the United States direct energy use by households accounts for approximately $38 \%$ of overall US $\mathrm{CO}_{2}$ emissions [1]. In various cities in Japan, urban residential carbon emissions accounts for more than $15 \%$ of the total urban emission [2]. The end energy consumption by Chinese residents ranks the second, only next to industrial energy consumption; residential energy consumption accounts for $12 \%$ of total energy consumption in 2015[3].

Households are the consumption body of end products and services, whose energy consumption and carbon emissions are attracting increasing attention of and discussions among researchers. International and Chinese scholars have carried out numerous researches on the issue, covering the impact factors of household carbon emissions, the negative impact on the environment and the calculation method. A range of studies have shown that the direct carbon emissions from household energy consumption account for a large proportion of household direct carbon emissions [4-7].

With continuous urbanization, it is expected that China's urbanization rate will reach $70 \%$ by 2030 . By then, the huge population size will make urban communities a key area for carbon reduction. In this context, it is of great significance to focus on direct carbon emissions of household energy consumption, exploring the impact factors and studying measures for energy saving and emission reduction. Based on the Consumer Lifestyle Approach (CLA), this study conducted a questionnaire survey obtaining first-hand data for a quantitative analysis of the direct carbon emission of household energy consumption. It explores the impact mechanism, and further suggests adaptive planning strategies for the development of low-carbon communities.

\section{Method and data}

\subsection{The Consumer Lifestyle Approach}

The Consumer Lifestyle Approach was proposed by Bin and Dowlatabadi in 2005 to explore the relationship between consumer activities and environmental impacts in the United States, and it has been widely used in research ever since. The basic premise underlying CLA is that better public policies will be designed by understanding individual behavior of consumers. The term "Consumer" in CLA refers to the entity that purchases and uses products and services for the purpose of individual or household consumption. "Lifestyle" refers to a way of living that influences and is reflected by one's consumption behavior. This approach builds an intrinsic link between the external environment, personal choices, household characteristics, consumer choices, and the consequences of consumer energy use behavior to study carbon emissions, and to correlate household consumption expenditures with relevant industry sectors, thereby enabling a calculation of household carbon emissions according to household's consumption expenditure and the carbon intensity of corresponding

longbinzhu@hotmail.com; *huangy@njupt.edu.cn 
departments. However, understanding consumers is made complicated by many interacting factors, many of which evolve over time in response to circumstances. The CLA approach attempts to provide an interdisciplinary framework to explicitly identify the multitude of interacting factors. [8]

\subsection{Data acquisition and indicator framework}

The data of this study was mainly obtained through interviews and questionnaires. The survey samples are made up of different communities and households. Communities were selected to meet the requirements of CLA approach for different types, sizes, building ages and living groups, covering the old residential areas,

Table 1. Indicators for the survey of carbon emissions from household energy consumption

\begin{tabular}{l|l|l}
\hline Variables & Indicators & Sub-indicators \\
\hline $\begin{array}{l}\text { dependent } \\
\text { variables: } \\
\text { carbon emission }\end{array}$ & $\begin{array}{l}\text { direct carbon emission from } \\
\text { household energy } \\
\text { consumption }\end{array}$ & $\begin{array}{l}\text { household annual electricity, water and gas } \\
\text { consumption }\end{array}$ \\
\hline $\begin{array}{l}\text { independent } \\
\text { variables: }\end{array}$ & $\begin{array}{l}\text { community characteristics; } \\
\text { housing characteristics; }\end{array}$ & $\begin{array}{l}\text { community size, floor area ratio, building age; } \\
\text { housing types, areas, number of rooms, living floors; } \\
\text { air conditioning habits, household work/rest schedules; } \\
\text { household regular residents, household structure, } \\
\text { average age, household income, average adult education } \\
\text { level }\end{array}$ \\
\hline
\end{tabular}

\subsection{Carbon emission calculation method}

The direct household energy consumption in this study refers to fossil fuels (oil, coal, gas, etc.) consumed in the household range, as well as end energy products such as electricity, water, and heat (central heating) as suggested by relevant researches. [9] The survey of the current situation of the communities finds that the main household energy consumption products are gas, electricity and water. The carbon emission calculation is based on the emission coefficient method proposed in the IPCC Guidelines for the Inventory of Greenhouse Gas Carbon Emission. The basic formula is: $\mathrm{CE}=\mathrm{EF} * \mathrm{AD}$, where $\mathrm{CE}$ refers to the carbon emissions of individual activity, EF refers to the carbon emission coefficient, and $\mathrm{AD}$ refers to the energy consumption. Direct carbon emissions from household energy consumption are the sum of the carbon emissions from different energy consumptions. With reference to the "National Energy Saving and Emission Reduction Handbook" issued by the Ministry of Science and Technology of China [10], the carbon emission coefficients used in this study is as in Table II:

Table 2. Carbon emission categories and coefficients

\begin{tabular}{l|c|c|l}
\hline Categories & $\begin{array}{l}\text { Consumption } \\
\text { Unit }\end{array}$ & $\begin{array}{l}\text { Emission } \\
\text { Coefficient }\end{array}$ & Unit \\
\hline water & $\mathrm{t} /$ month & 0.30 & $\mathrm{KgCO}_{2} / \mathrm{t}$ \\
\hline electricity & $\mathrm{kwh} /$ month & 0.96 & $\mathrm{KgCO}_{2} / \mathrm{kwh}$ \\
\hline gas & $\mathrm{m} 3 /$ month & 2.67 & $\mathrm{KgCO}_{2} / \mathrm{m} 3$ \\
\hline
\end{tabular}

resettlement housing areas, new commercial housing areas, etc. Households were chosen to cover households of different housing types and sizes and different family types. The study selected 5 communities in Nanjing, China. From February to May 2018, a questionnaire survey was conducted with 200 questionnaires distributed and 173 returned valid.

The CLA indicator framework of the study includes carbon emissions (dependent variables) and impact factors (independent variables), of which the dependent variable refers to the direct carbon emission of household energy consumption; the independent variables include four characteristics: community, housing, lifestyle and family characteristics (see Table 1).

\subsection{Data Analysis Method}

In the analysis of impact factors, this paper mainly used single factor analysis of variance, one-way linear regression and multiple linear regression in SPSS17.0. Firstly, one-way analysis of variance was conducted to determine the effective factors that have an impact on the direct carbon emissions of household carbon consumption. Secondly, the linear regression analysis of each factor was performed before multivariate regression to determine the linear relationship between each independent variable and dependent variable. Finally, a multivariate analysis was conducted to determine the combined effects of various factors on the direct carbon emissions of household energy consumption and their respective effects on carbon emissions.

\section{Carbon emission characteristics of household energy consumption and the impact factors}

\subsection{Characteristics of direct carbon emissions from household energy consumption}

The survey of the five communities in Nanjing, China shows that the annual direct carbon emission from energy consumption is $2489.36 \mathrm{~kg}$ per household, and $796.73 \mathrm{~kg}$ per capita. The proportion of household electricity, gas, and water carbon emission is 82:17:1, and household electricity consumption is the most 
important aspect affecting the direct carbon emissions of household energy consumption.

\subsection{Determination of impact factors}

One-way analysis of variance was used to determine whether a single factor had a significant effect on the dependent variable. The premise of one-way ANOVA is that the sample as a whole should satisfy the normal distribution. Therefore, the homogeneity test of variance should be performed before the one-way ANOVA. Only when the Sig value of the variance homogeneity test is $>0.05$ can the one-way variance be determined. If the significance level $\mathrm{p}$ is $<0.05$, the null hypothesis is rejected, indicating that the factor has a significant impact on the direct carbon emissions of household energy consumption.

The analysis showed that the factors of household work/rest schedule and household average age did not pass the homogeneity test ( $\mathrm{Sig}=0.000)$, and community size $(\mathrm{F}=1.051, \quad \mathrm{P}=0.352)$, building age $(\mathrm{F}=4.982$, $\mathrm{P}=0.008)$, and building type and size $(\mathrm{F}=6.998$, $\mathrm{P}=0.009)$, floor $(\mathrm{F}=1.323, \mathrm{P}=0.169)$ did not pass the significance level test of 0.05 , indicating that the above six factors have no significant effect on direct carbon emissions from household energy consumption. The other eight factors, namely floor area ratio, housing area, number of rooms, air-conditioning habit, household regular residents, household structure, annual household income, and average adult education level are effective impact factors on direct carbon emissions from household energy consumption.

Table 3. Multiple linear regression results

\subsection{Significant impact factors and their characteristics}

In order to screen the most influential factors, this study mainly used backward regression to gradually remove the factors with $\mathrm{p}>0.02$ as floor area ratio, household structure, adult average educational level and household area, and retain the main factors. The results of the analysis (see Table 3 ) showed a significant $\mathrm{P}$ value of 0.000 , and the regression coefficient $t$ of each factor passed the test $(\mathrm{p}<0.02)$, indicating that the selected factors were significantly correlated with direct carbon emissions from household energy consumption. The larger the $F$ value is, the better the regression effect should be. The data shows that the F value is 114.575 , which shows the regression effect is good. The R-square indicates the proportion of the total variation of the dependent variable explained by all the independent variables, indicating that the entire equation can account for $73.2 \%$ of the household energy carbon emissions. According to the regression coefficients, it can be seen that there are four factors that are positively correlated with the direct carbon emissions of household energy consumption. The absolute value of the standardized regression coefficient in the standard coefficient column can be used to compare the impact of each factor on household carbon emissions, i.e. household income $(0.425)>$ household regular residents $(0.327)>$ number of rooms $(0.239)>$ air conditioning habits $(0.132)$. It can be seen that household characteristics have the most significant impact on the direct emission of household energy consumption.

\begin{tabular}{l|l|l|l|l|l}
\hline & $\begin{array}{l}\text { Regression } \\
\text { coefficient }\end{array}$ & Std. Error & $\begin{array}{l}\text { Standardized } \\
\text { coefficient }\end{array}$ & t & Sig. \\
\hline (constant) & -288.399 & 143.778 & & -2.006 & 0.01 \\
Household annual income & 312.693 & 38.538 & 0.425 & 8.114 & 0.000 \\
Household regular residents & 191.456 & 28.981 & 0.327 & 6.606 & 0.000 \\
Number of rooms & 273.842 & 54.384 & 0.239 & 5.035 & 0.000 \\
Air-conditioning habits & 108.861 & 41.039 & 0.132 & 2.653 & 0.009 \\
\hline
\end{tabular}

（ $\mathrm{R}$ square $=0.732, \mathrm{~F}=114.575)$

Based on the CLA approach, the characteristics of direct carbon emissions from household energy consumption were quantitatively analysed and the significant impact factors were extracted through SPSS data analysis. The following conclusions were drawn: (1) Annual average carbon emission from energy consumption is $2489.36 \mathrm{~kg}$ per household and $796.73 \mathrm{~kg}$ per capita. The proportion of household electricity, gas, and water carbon emission is $82: 17: 1$; (2) Household income, household regular residents, number of rooms, and air-conditioning habits are the four most significant factors; (3) floor area ratio, household structure, average adult educational level, and household area are other effective factors affecting the direct carbon emissions from household energy consumption.

\section{Adaptive Strategies for Low Carbon Community Planning}

Based on the study of the characteristics and impact factors of direct carbon emissions from household carbon consumption, the key impact factors are determined. On this basis, three strategies for the planning and construction of low-carbon communities are proposed as to improve direct controllable factors, influence indirect controllable factors, as well as to promote public participation. 


\subsection{Improve direct controllable factors through planning}

The direct controllable factors include community characteristics and housing characteristics. Floor area ratio, household area and number of rooms are the factors affecting the direct carbon emissions of household energy consumption, of which household area and number of rooms are positively correlated with the carbon emissions, while the floor area ratio negatively correlated with the carbon emissions. The study finds that an ideal model for low-carbon communities is that the household area is small, the number of rooms is fewer but the floor area ratio is high. However, the floor area ratio is more affected by land use planning. Besides, relevant researches suggest that the difference in the carbon emissions of household energy consumption for different floor area ratio residential areas is jointly affected by such social factors as household demographics and income. [11] Therefore, no direct measures are needed concerning floor area ratio in community planning. Measures should be focused on efficient and compact designing. On the basis of acknowledging future residents and understanding their demands in life, a design with smaller area but more efficient use of rooms, combined with low-carbon technology designing, will help reduce residents' use of electricity for heating and cooling.

\subsection{Influence indirect controllable factors by planning to guide low-carbon life}

Relevant researches on carbon reduction mechanism through urban planning found that planning for rational urban spatial structure will guide and transform urban residents' living habits and concepts and gradually cultivate urban residents' low-carbon behaviors and lifestyles, so that ultimately the goal of carbon emission reduction will be achieved [12]. At community level, this study further found that household income, household regular residents, air-conditioning habits, household structure, and average adult education level are the impact factors of the carbon emission from household carbon consumption. Although these factors cannot be directly controlled by planning, certain planning and designing measures can lead residents so as to change their consumer habits. These measures may include proper housing type and size designing to control regular residents and planning and designing for microclimate and indoor ventilation improvement so that residents' air-conditioner using habits may be altered.

\subsection{Promote public participation for a joint effort for low-carbon community construction}

This study has found that residents' lifestyle choices and household characteristics are the most significant impact factors affecting carbon emissions. High-income households also have higher average household carbon emissions. As residents' income continues to increase, there is an urgent need for active public participation.
Low-carbon awareness cultivation and residents' participation as an innovation of community work requires initiative organization of community management. For another, it needs the support of external forces such as experts and social groups to guide residents to participate in the whole process of lowcarbon community construction, from decision-making, planning and designing, implementation to the operation of the communities. At the same time, governments' financial and policy support are also indispensable. Policy and capital integration should be strengthened, and street or community should play the key roles. With full understanding of a community's carbon emissions, the carbon reduction targets and measures should be set according to local conditions, and public participation should be encouraged for a joint effort for low-carbon communities.

\section{Conclusions}

Based on the Consumer Lifestyle Approach, this study quantitatively analyzes the characteristics of direct carbon emissions from household energy consumption and extracts the significant impact factors through SPSS data analysis. Household income, household regular residents, number of rooms, and air-conditioning habits are found to be the four most significant impact factors. And floor area ratio, household structure, average adult educational level, and household area are found to be other effective factors affecting the emissions. Due to the difficulties in data acquisition, this study only employed data from questionnaire survey, lacking data from power, water and gas supply departments for verification that should otherwise be more conducive to the improvement of the conclusion. Nevertheless, the research results suggest some adaptive planning strategies as to improve direct controllable factors, influence indirect controllable factors as well as promote public participations so that a community's energy conservation and emission reduction targets can be achieved.

\section{References}

1. Dietz, T., Gardner, G. T., Gilligan, J., et al. (2009) Household actions can provide a behavioral wedge to rapidly reduce US carbon emissions. J. Proceedings of the National Academy of Sciences 106(44):18452-18456.

2. Shimada, K., Tanaka, Y., Gomi K., et al. (2007) Developing a long-term local society design methodology towards a low-carbon economy: An application to Shiga Prefecture in Japan. J. Energy Policy 35(9): 4688-4703.

3. China National Bureau of Statistics. China Statistical Yearbook 2017. http://www.stats.gov.cn/tjsj/ndsj/2017/indexch.htm.

4. Wang, Q., Zhang, Z., Qu, J. (2013) A review of the research on household carbon emission. J. Advances in Earth Science 28(12):1305-1312. 
5. Ye, H., Pan, L., Chen, F., et al. (2010) Direct carbon emission from urban residential energy consumption: A case study of Xiamen, China. J. Acta Ecologica Sinica 30(14):3802-3811.

6. Yang, X., Ge, Y., Zeng, H. (2010) The household carbon emission analysis under individual consumer behavior. J. China Population, Resources and Environment 20(5):35-40.

7. Zhang, Y., Qin, Y. (2011). Review on research of impact factors of carbon emissions due to household energy consumption. J. Economic Geography 31(2):284-288.

8. Bin, S., Dowlatabadi, H. (2005) Consumer lifestyle approach to US energy use and the related $\mathrm{CO} 2$ emissions. J. Energy Policy 33(2):197-208.

9. Zeng, J., Zhang, Z., Qu J., et al. (2012) Analysis and evaluation of methods for household carbon emissions calculation. J. Progress in Geography 31(10):1341-1352.

10. China 21st Century Agenda Management Center of Department of Social Development and Technology of Ministry of Science and Technology. (2007) Practical Manual for National Energy Saving and Emission Reduction. Social Sciences Academic Press, Beijing.

11. Wang, W., Li, J. (2017) Correlation between residential density and carbon emissions caused by household energy consumption: A case study on Caoyang Xincun, Shanghai. J. City Planning Review 41(6): 83-91.

12. Jiang, H., Xiao, R., Wu, J. (2013) The impact pattern of urban household carbon emission and implications for the low-carbon resident community planning: A case study of Guangzhou. J. Modern Urban Research (2):100-106. 